\title{
ISOLATION OF ETHYLBENZENE FROM AN OKLAHOMA PETROLEUM ${ }^{1}$
}

\author{
By Joseph D. White ${ }^{2}$ and F. W. Rose, Jr. ${ }^{2}$
}

\section{ABSTRACT}

Ethylbenzene having a purity of about 95 mole percent has been isolated from an Oklahoma petroleum. The density, refractive index, boiling point, and behavior on freezing of this sample have been determined and compared with the same properties of a very pure sample of synthetic ethylbenzene. A photograph of the infrared absorption spectrum of the ethylbenzene from petroleum has also been obtained. It is found that ethylbenzene constitutes about 0.03 of 1 percent of the crude petroleum.

The freezing points and composition of eutectic mixtures of ethylbenzene with meta- and para-xylene have been determined.

\section{CONTENTS}

I. Introduction

II. Methods and procedure

639

.

III. Properties of the isolated ethylbenzene

IV. Content of ethylbenzene in the crude oil

V. Acknowledgment.

\section{INTRODUCTION}

With one exception, ethylbenzene has heretofore escaped detection by all investigators of the composition of petroleum. In a study of various petroleums (including a sample from Pennsylvania), Tausz ${ }^{3}$ oxidized the distillation fractions boiling within a range which included the boiling point of ethylbenzene. From these he obtained, among other products, some benzoic acid which he assumed indicated the presence of ethylbenzene. Other workers, including Mabery, ${ }^{4}$ have sought for ethylbenzene in vain.

This paper is an account of the isolation of ethylbenzene itself from an Oklahoma petroleum. ${ }^{5}$ The separation of this hydrocarbon from the fraction in which it collected during distillation was accomplished by first extracting it, along with the xylenes, with liquid sulphur dioxide, and next subjecting the extract to a systematic crystallization and distillation. From the resulting ethylbenzene fraction, almost pure ethylbenzene was isolated by selective sulphonation and hydrolysis. Final purity was attained by repeating the sulphonation or by fractional crystallization.

1 Financial assistance has been received from the research fund of the American Petroleum Institute. This work is part of Project No. 6, The Separation, Identification, and Determination of the Constituents of Petroleum.

Research associate representing the American Petroleum Institute.

Tausz, J., Zeit. angew. Chem., vol. 32 (I), p. 361, 1919.

- Mabery, C. F., Proc. Am. Acad. Arts Sci., vol. 31, p. 38, 1895.

- For description and properties of the oil see Washburn, E. W., Bruun, J. H., and Hicks, M. M., B.S. Jour. Research, vol. 2, p. 469, table 1, 1929. 


\section{METHODS AND PROCEDURE}

The 45 liters of petroleum which distilled between $130^{\circ}$ and $145^{\circ} \mathrm{C}$. was extracted with liquid sulphur dioxide as previously described. ${ }^{6}$ About 12 liters of extract was obtained, which consisted chiefly of a mixture of xylenes. Traces of aromatic hydrocarbons remaining in the immiscible or extracted fraction were finally removed with concentrated sulphuric acid.

Upon fractional crystallization of the extract, mother liquors from successive crystallizations were obtained which, while decreasing but slowly in refractive index, froze at surprisingly low temperatures; those from the final crystallizations froze far below the known freezing points of the xylene eutectics. This is to say, fractions accumulated which from their indices obviously contained aromatic hydrocarbons, but which from their freezing points obviously contained others in addition to the xylenes. When fractionation by crystallization was no longer feasible the mother liquors were further fractionated by extraction, alternated with distillation. This procedure yielded finally a fraction of $625 \mathrm{ml}$ which boiled at $136^{\circ} \mathrm{C}$., froze initially at $-96^{\circ} \mathrm{C}$. (with a second halt at $-108^{\circ} \mathrm{C}$.), and had a refractive index $n \underset{\mathrm{D}}{25}$ of 1.480 . These properties, as well as the odor, indicated that the material was impure ethylbenzene. At this stage of purification the major impurity was $m$-xylene. In order to remove most of this constituent, a sample of the fraction was sulphonated at $0^{\circ} \mathrm{C}$. in the manner described elsewhere. ${ }^{6}$

The acid layer was separated from the unattacked oil and after dilution with an equal volume of water it was distilled with steam. This treatment resulted in the distillation of hydrocarbon as rapidly as it was liberated by hydrolysis from the sulphonic acid. The temperature of hydrolysis was regulated by boiling the acid solution when at the required concentration. The greater part of the recovered hydrocarbon was liberated thus at $130^{\circ}$ to $135^{\circ} \mathrm{C}$. This fraction was shown to consist almost entirely of $m$-xylene. However, a considerable portion collected when the temperature within the still was maintained at $155^{\circ}$ to $157^{\circ} \mathrm{C}$., the range (previously established) at which ethylbenzenesulphonic acid most readily hydrolyzes. Treatment of the remaining ethylbenzene stock in a similar manner yielded finally various fractions, the properties of which are listed in table 1.

TABLE 1.-Fractions obtained by sulphonating the ethylbenzene stock at $0^{\circ} \mathrm{C}$.

\begin{tabular}{|c|c|c|c|c|}
\hline Fraction & $\begin{array}{l}\text { Vol- } \\
\text { ume }\end{array}$ & $\begin{array}{l}\text { Temper- } \\
\text { ature of } \\
\text { hydroly- } \\
\text { sis }\end{array}$ & $\begin{array}{l}\text { Refractive in- } \\
\quad \operatorname{dex} n_{\mathrm{D}}^{25} \\
\text { (uncorrected) }\end{array}$ & $\begin{array}{l}\text { Initial freezing } \\
\text { point } \\
\text { (uncorrected) }\end{array}$ \\
\hline 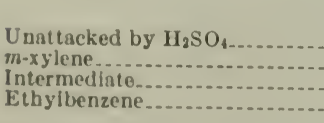 & $\begin{array}{r}m l \\
375 \\
125 \\
10 \\
95\end{array}$ & $\begin{array}{l}{ }^{\circ} \mathrm{C} . \\
130-135 \\
135-155 \\
155-160\end{array}$ & $\begin{array}{r}1.4755 \\
1.4944 \text { to } 1.4941 \\
1.4941 \text { to } 1.4938 \\
1.4931\end{array}$ & $\begin{array}{r}{ }^{\circ} \mathrm{C} . \\
-48.5 \text { to }-50.3 \\
-97.3\end{array}$ \\
\hline
\end{tabular}

- White, J. D., and Rose, F. W., B.S.Jour. Research, vol. 9, pp. 714, 716, 1932. 
The fraction obtained by hydrolysis at $155^{\circ}$ to $160^{\circ} \mathrm{C}$. was identified with greater certainty as ethylbenzene when a portion of it was oxidized with neutral potassium permanganate. Some carbon dioxide and a small amount (less than 5 percent) of isophthalic acid was formed, but the major part of the product was benzoic acid. This was considered to be confirmatory evidence for the presence of ethylbenzene.

The $375 \mathrm{ml}$ fraction of oil left unattacked by sulphonation at $0^{\circ} \mathrm{C}$. was now sulphonated at room temperature (about $30^{\circ}$ C.) for 48 hours. An equal volume of acid was used and it was introduced dropwise with constant stirring. Treated in this manner, only $115 \mathrm{ml}$ remained unattacked. Its properties indicated that it was probably a mixture of naphthenes and isononanes. It was combined with the main stock of petroleum distillate previously freed from aromatic hydrocarbons and is now in the process of analysis.

The acid layer (from sulphonation at room temperature), when diluted and distilled as before, yielded an additional $35 \mathrm{ml}$ of impure $m$-xylene and $200 \mathrm{ml}$ of ethylbenzene which was liberated at $146^{\circ}$ to $158^{\circ} \mathrm{C}$.

The various samples of ethylbenzene obtained by this hydrolysis ranged in freezing points from $-97.3^{\circ}$ to $-99.6^{\circ} \mathrm{C}$. as measured with a calibrated thermocouple of five junctions. ${ }^{7}$ They were finally purified either by resulphonation and hydrolysis or by crystallization from a propane solution.

Resulphonation was carried out at room temperature. Upon hydrolysis, practically no oil was obtained within the range of temperature at which $m$-xylene is liberated, but nearly a third of the product of hydrolysis was released between $145^{\circ}$ and $155^{\circ} \mathrm{C}$. While this fraction consisted mainly of ethylbenzene, it nevertheless contained a considerable amount of $p$-xylene, as indicated by an initial halt in the cooling curve at a temperature well above the freezing point of ethylbenzene. This evidence of the presence of $p$-xylene was supported by the fact that its characteristic odor could be detected in the sample notwithstanding the pronounced odor of ethylbenzene. The refractive index of the sample, however, was higher by about 0.0001 than that for a sample of either $p$-xylene or ethylbenzene (which have nearly the same index). This would indicate that a small quantity of $m$-xylene was also present. The fraction was therefore rejected, and only the final two thirds of the product from hydrolysis was preserved. This was obtained between $155^{\circ}$ and $160^{\circ} \mathrm{C}$. and comprised about half of the sample the properties of which are given in table 2.

The presence of $p$-xylene in the fraction liberated by hydrolysis between $145^{\circ}$ and $155^{\circ} \mathrm{C}$. was anticipated from an experiment made to ascertain at what temperature $p$-xylene is regenerated by steam from its sulphonic acid. The results of the experiment showed that most of the $p$-xylene is obtained at a temperature between $145^{\circ}$ and $147^{\circ} \mathrm{C}$. Hence, it is to be observed that the ranges in temperature of hydrolysis of the sulphonic acids of $p$-xylene and ethylbenzene are

7 These freezing points are doubtless too low by as much as a degree. At temperatures near its freezing point ethylbenzene becomes quite viscous and tends to supercool to a great extent before crystallizing. Forcing the supercooled sample to begin to freeze by immersing in it a rod chilled with liquid air causes a small amount of solid phase to form which is glassy in texture. Usually, several minutes elapse before the solid phase comes to equilibrium with the unfrozen liquid wetting the thermometer as shown by a constantly rising temperature. If along with supercooling the rate of cooling is rapid, as it was in the above cases, and the sample is impure, the initial freezing point cannot be obtained. 
quite close together. With mixtures of the two, at least, these temperatures overlap. Furthermore, the two hydrocarbons react with sulphuric acid to about the same extent. Therefore, their separation from each other by sulphonation and hydrolysis is not sharp, and is at best fractional in nature.

Another portion of the ethylbenzene obtained from the initial sulphonation was purified by crystallization from a propane solution containing 3 parts by volume of the solvent to 1 of ethylbenzene. This solution was cooled to the temperature of liquid air in a centrifuge which could be operated at that temperature. ${ }^{8}$ Crystallization took place and when a considerable amount of solid phase had appeared the mush was centrifuged at once. The crystals which were retained were partly melted and again centrifuged. Two thirds of the original sample was recovered in the crystal fraction. On cooling, this sample and the one from resulphonation behaved almost identically. Accordingly, the two samples were combined into one sufficiently large for careful measurements of its physical properties.

\section{PROPERTIES OF THE ISOLATED ETHYLBENZENE}

In table 2, the physical properties of the isolated ethylbenzene are compared with those of synthetic ethylbenzene reported in the literature. The table also shows a similar comparison made with a very pure sample of ethylbenzene obtained from the Bureau International des Etalons Physico-Chimiques in Brussels. The similarity in properties of the two samples serves well to identify the hydrocarbon isolated from petroleum.

TABLE 2.-The ph'sical constants of samples of ethylbenzene compared with previously reported constants for synthetic ethylbenzene

\begin{tabular}{|c|c|c|c|c|c|}
\hline Sample & $\begin{array}{l}\text { Specific } \\
\text { gravity } \\
d_{4}^{20}\end{array}$ & $\begin{array}{l}\text { Refractive } \\
\text { index } \\
n_{\mathrm{D}}^{25}\end{array}$ & $\begin{array}{c}\text { Normal } \\
\text { boiling } \\
\text { point }\end{array}$ & $\begin{array}{l}\text { Melting } \\
\text { point (in } \\
\text { dry air) }\end{array}$ & $\begin{array}{l}\text { Mole } \\
\text { percent } \\
\text { ethyl- } \\
\text { benzene }\end{array}$ \\
\hline $\begin{array}{l}\text { From petroleum } \\
\text { From Bureau des Etalons Phys.-Chim. (Timmer- } \\
\text { mans) }\end{array}$ & $\begin{array}{r}10.86679 \\
1.86770 \\
56.86690\end{array}$ & 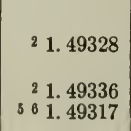 & $\begin{array}{ll} & \circ C . \\
& \stackrel{1}{3} 136.05 \\
& \\
3 & 136.28 \\
3 & 136.15\end{array}$ & $\begin{array}{l}\circ C . \\
-96.15 \\
-95.12 \\
8-94.4\end{array}$ & - \\
\hline
\end{tabular}

$1 \pm 0.00001$. Determined by the Division of Weights and Measures of this Bureau.

\pm 0.00005 . Determined with a calibrated Abbé refractometer (Valentine design).

t 0.05 . Determined in a Cottrell boiler. The precision shown is for comparative purposes only.

- Temperature at which last of solid eutectic disappeared. (See fig. 1.)

- See Timmerm sns and Martin, J.chim. phys., vol. 23, pp. 753-759, 1926.

- Calculated from values given for $15^{\circ} \mathrm{C}$.

As a test of purity of the isolated ethylbenzene, its behavior on freezing was determined. Its time-temperature cooling curve and melting curve ${ }^{9}$ are shown in figure 1 as curve $I I$.

Curve $I$ in figure 1 shows the behavior on cooling of a solution containing 95 mole percent of pure ethylbenzene and 5 mole percent

\footnotetext{
' For description of the centrifuge see Leslie, R. T., B.S.Jour. Research, vol. 10 (RP 552), p. 611, 1933.

- These curves as well as others of a similar nature appearing in this report were determined with the 25 ohm platinum resistance thermometer used by Mair in his work on the physical constants of synthetic normal hydrocarbons. (See B.S.Jour. Research, vol. 9, p. 458, 1932.) The samples were cooled or warmed very slowly in a vacuum jacketed tube of $40 \mathrm{ml}$ capacity and wore forced to begin crystallizing when they were but slightly supercooled.
} 
of pure $p$-xylene. ${ }^{10}$ An initial break in the curve at $-84^{\circ} \mathrm{C}$. (not shown in the figure) indicated that $p$-xylene crystals first appeared at that temperature. The prolonged halt in cooling shown by the curve marks the freezing point $\left(-95.88^{\circ} \mathrm{C}\right.$.) of the eutectic mixture of these two compounds. This mixture contains (as calculated from the lowering of the freezing point of ethylbenzene) 97.4 mole percent of ethylbenzene and 2.6 mole percent of $p$-xylene.

A similar cooling curve for a solution of 85 mole percent of ethylbenzene and 15 mole percent of $m$-xylene showed that ethylbenzene crystals first appeared at $-100.05^{\circ} \mathrm{C}$. and that the eutectic mixture froze at $-101.05^{\circ} \mathrm{C}$. From the lowering of the freezing point of ethylbenzene in this case, it was computed that ethylbenzene and $m$-xylene are present in the eutectic in the ratio of about 81 to 19 by weight. ${ }^{11}$

Comparison of the cooling curves shown in figure 1 revealed the fact that the sample of ethylbenzene from petroleum was impure.

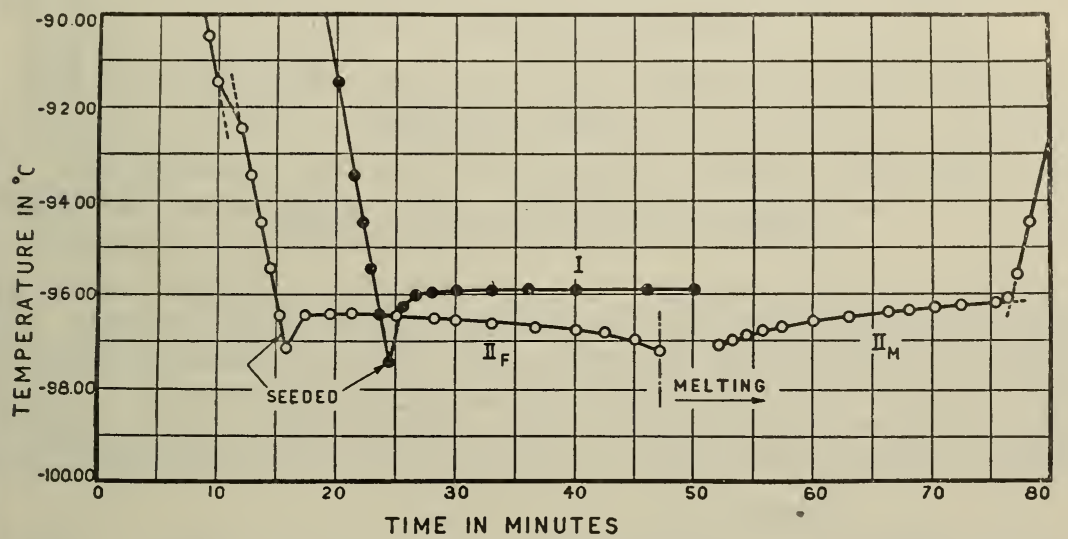

FIGURE 1.-Comparison of the freezing and melting curves of ethylbenzene from petroleum with the freezing curve of a synthetic mixture of ethylbenzene and p-xylene.

Curve $I$, synthetic mixture; curve $I I$, ethylbenzene from petroleum.

That it contained only a minute amount of $m$-xylene was evidenced by the fact that its eutectic point at $-96.15^{\circ} \mathrm{C}$. was $5^{\circ}$ above the eutectic point of $m$-xylene and ethylbenzene. The sample did contain, however, an appreciable amount of $p$-xylene as indicated by its initial freezing point near $-92^{\circ} \mathrm{C}$. and by the fact that its eutectic mixture froze but $0.27^{\circ} \mathrm{C}$. below the eutectic point of pure ethylbenzene and $p$-xylene. The only conclusion that could be drawn from these data regarding the degree of purity of the sample was that it contained less than 96.5 mole percent of ethylbenzene (the eutectic

${ }^{10}$ The ethylbenzene used in this experiment was the best sold by the Eastman Kodak Co. It was purifled further by selective sulphonation and hydrolysis and finally by distilling through an efficient column packed with jack chain. The properties of the sample used were:

$$
d_{4}^{20}=0.86746, n_{D}^{25}=1.49327, B . P .=136.2^{\circ} \mathrm{C} . M . P .=-95.15^{\circ} \mathrm{C} .
$$

The $p$-xylene used, and the $m$-xylene used in a later experiment were very pure samples obtained by us from petroleum. Their properties are listed in tables 3 and 4, B.S. Jour. Research, vol. 9, pp. 717, 718, 1932. 11 The composition of this eutectic, as well as that for the $p$-xylene-ethylbenzene eutectic, was calculated by equation (47), p. 203, Washburn, Principles of Physical Chemistry, McGraw-Hill Book Co., 1921. For the heat of fusion of ethylbenzene the value of Parks and Huffman (Ind. Eng. Chem., vol. 23, p. 1138, 1931) was used. The difference in the molal heat capacities of its liquid and crystalline states was neglected. 
composition) and probably more than 95 mole percent as judged by comparing its initial freezing point with that of a prepared solution containing that amount of ethylbenzene.

A more exact analysis was carried out in the following manner: Equal weights of the sample isolated from petroleum and of pure

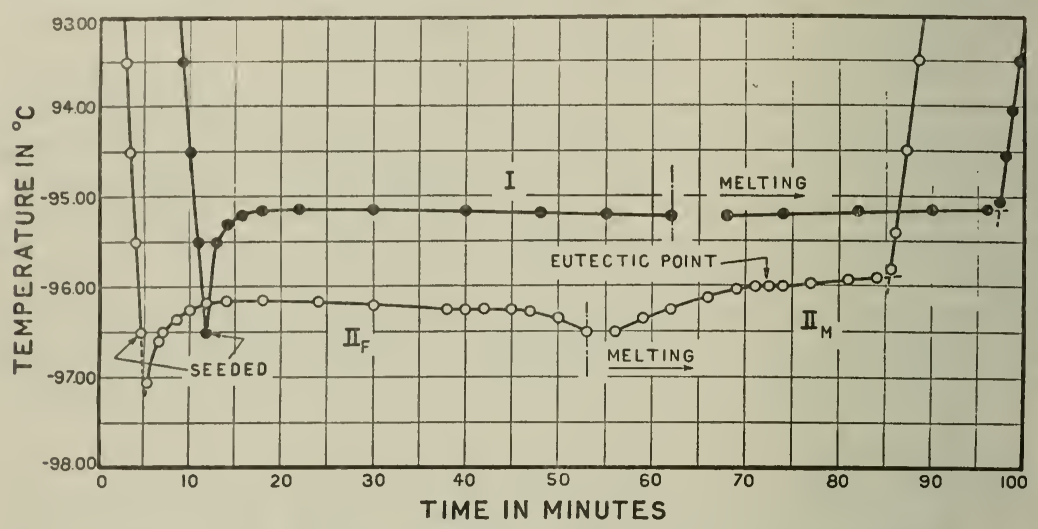

FIGURE 2.-Freezing and melting curves of samples of ethylbenzene.

Curve I, from Bureau des Étalons Physico-Chimiques; curve II, mixture containing equal weights of ethylbenzene from petroleum and of pure ethylbenzene.

ethylbenzene (Timmermans) were mixed to give a solution somewhat richer in ethylbenzene than its eutectic mixture with $p$-xylene. On cooling this solution, the first solid phase to appear was ethylbenzene. The cooling and melting curves of the solution are shown as curve $I I$ in figure 2, where it is compared with a similar curve (curve $I$ ) for a sample of pure ethylbenzene. The point on curve $I I$ indicating the

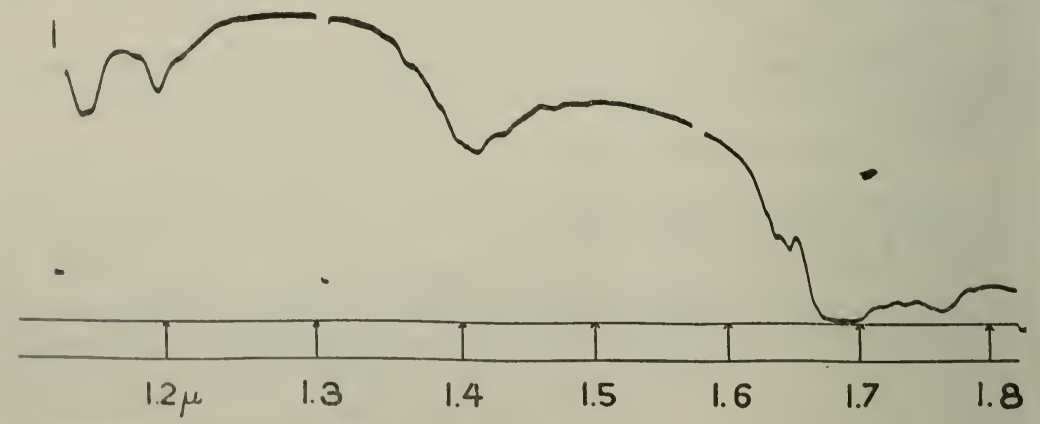

FIGURE 3.-The infrared absorption spectrum of the isolated ethylbenzene.

The spectrum, produced by ethylbenzene in a cell of $4 \mathrm{~mm}$ depth, is imposed on the energy emission curve of a tungsten fllament lamp. A bsorption in the region of $1.2 \mu$ is due to the ethyl group and that near $1.14 \mu$ is attributed to the aromatic nucleus.

temperature at which the second solid phase appeared is somewhat indistinct but is perceptible. This was to be expected in view of the fact that the freezing points of ethylbenzene and of its eutectic with $p$-xylene are so close together.

From the curves it was found that the impurity of the prepared solution caused the freezing point of ethylbenzene to be lowered by $0.7 \mathrm{~S}^{\circ} \mathrm{C}$. It follows, then, by computation that this solution contained 
97.3 mole percent of ethylbenzene and the original sample (which had twice the impurity) contained 94.6 mole percent of ethylbenzene.

Figure 3 shows the infra-red absorption spectrum of ethylbenzene isolated from petroleum. The photograph of the spectrum was obtained by U. Liddel, of the Fixed Nitrogen Laboratory of the U.S. Bureau of Chemistry and Soils.

IV. CONTENT OF ETHYLBENZENE IN THE CRUDE OIL

The total volume of ethylbenzene isolated from the fraction of petroleum amounted to nearly $300 \mathrm{ml}$. This, for the most part, was obtained from the distillation fraction boiling within the range of $130^{\circ}$ to $136^{\circ} \mathrm{C}$., and constitutes about 0.015 percent by weight of the crude oil. Allowing for losses of materials during the work, it is estimated that the content of ethylbenzene in the crude oil is more nearly, but not greater than, 0.03 percent by weight.

\section{ACKNOWLEDGMENT}

The authors desire to express their appreciation for the technical advice of Dr. E. W. Washburn, Chief of the Division of Chemistry at this Bureau, which they have followed in the course of this investigation.

Washington, March 9, 1933. 